\title{
PROJETO ARARA DE BRINQUEDO
}

"Haja, todavia, uma medida para descansos; senão, negados, criarão o ódio aos estudos e, em demasia, o hábito da ociosidade. Há, pois para aguçar a inteligência das crianças, alguns jogos que não são inúteis desde que se rivalizem a propor, alternadamente, pequenos problemas de toda a espécie”. Quintiliano - primeiro século da Era Cristã.

(Gadotti, 1993, pg. 49)

\author{
Cátia Cristina Silva* \\ Clélia Regina Ramos** \\ Paulo Roberto Bortoli*** \\ René José Da Silva ${ }^{* * * *}$
}

Resumo: Atividades lúdico-pedagógicas são importantíssimas no desenvolvimento da criança, pensando nisso foi desenvolvido o Projeto "Arara de Brinquedo", em 2004, pela Editora ARARA AZUL (www.editora-arara-azul.com.br), um espaço dedicado à cultura e à diversidade, e que tem por objetivo disponibilizar, gratuitamente, software educacionais desenvolvidos especialmente para crianças surdas, mas, que também, podem ser utilizados por crianças ouvintes, oferecendo atividades que auxiliem no aprendizado da Língua Brasileira de Sinais (LIBRAS), da Língua Portuguesa e dos demais conteúdos curriculares e culturais a níveis do Ensino Pré-Escolar e Fundamental nas escolas e em clínicas, fundações, residências e em todos locais, onde quaisquer pessoas manifestem o desejo usá-los, desde que assumam o compromisso de respeitar as condições de Software de Domínio Público e de disclaimer definidas para os programas.

Palavras-chave: Língua Brasileira de Sinais (LIBRAS), alfabetização, educação especial, jogos educacionais, informática na educação.

Abstract: Leisurely-pedagogical activities are highly important for children

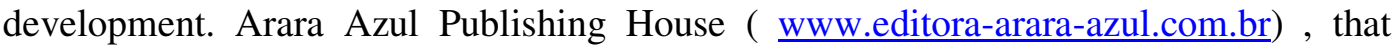
shelters an open forum for discussions on culture and diversity, is commited to those matter and has developed a project named "Arara de Brinquedo" in 2004. This project offers, by free download, educational software directed to deaf children, regardless its usebillity by hearing children too, offering activities that increase the skllis in Brazilian

\footnotetext{
* Professora de Ensino Fundamental com Estudos Adicionais no INES, Pedagoga com Especialização em Tecnologia Educacional

E-mail: admarara@uninet.com.br

** Jornalista, Especialista em Educação à Distância e Doutora em Semiologia

E-mail: editora@uninet.com.br

*** Professor, Especialista em Informática Educativa e Mestre em Educação

E-mail: prbortoli_educ@terra.com.br

**** Professora de Ensino Fundamental com Habilitação em Educação de Surdos

E-mail: secretaria@editora-arara-azul.com.br

V.3 No 1, Maio, 2005
} 
Sign Language/LIBRAS, Portuguese and another curricula skills to pre-schollar and first classes, that could be used in clinics, foundations, schools and every place that people want to use them, as far as they accept the commitment with Free Software roules and disclaimer of the software.

Keywords: Brazilian Sign Language (LIBRAS), alphabetization, special education educational games, Informatics in Education.

\section{HISTÓRICO}

O Projeto Arara de Brinquedo surgiu a partir do Projeto "Coleção Clássicos da Literatura em LIBRAS/Português em CD-ROM", através do qual a Editora ARARA AZUL, idealizadora e executora, distribuiu gratuitamente, com o apoio da IBM e com as parcerias da SEESP/MEC (Secretaria de Educação Especial do Ministério da Educação) e da FENEIS (Federação de Educação e Integração dos Surdos), 18 mil unidades de CDs, sendo que entre estes se encontram "Alice no País das Maravilhas", "Pinóquio" e "Aladim", direcionados a público infanto-juvenil. Devido a grande aceitação deste Projeto, que possui um Ambiente Virtual para sua avaliação (www.ibmcomunidade.com/libras), foi o amadurecendo da idéia de se criar um outro projeto direcionado às crianças surdas de 03 a 11 anos e, também, que surgiu a oportunidade de identificar, em todo território nacional, vários profissionais dedicados a pesquisa e produção de materiais direcionados a Surdos, entre estes um professor Especialista em Informática na Educação e com Mestrado em Educação na linha de pesquisa de novas tecnologias aplicadas a Educação. E, embora, este resida em Porto Alegre/RS e a Editora esteja sediada em Petropólis/RJ, a distância não constituiu barreira para a concretização e evolução do Projeto, sendo todos os contatos feitos exclusivamente através da Internet.

\section{JUSTIFICATIVA}

A implementação de um projeto destinado à produção e distribuição de programas pelo Projeto "Arara de Brinquedo" é justificada pela constatação da quase total inexistência de materiais educativos em mídia digital para crianças surdas, embora saibamos que software educacionais para crianças ouvintes estão cada vez mais sendo disponibilizados, tanto no mercado nacional como internacional. A intenção do Projeto é preencher esta lacuna e atingir um número ilimitado de surdos, familiares e instituições tais como Escolas Privadas e Escolas Públicas (Federais, Estaduais e Municipais) com alunos surdos, Associações de Surdos e todos que, de alguma forma, se dedicam ao desenvolvimento da educação dos surdos brasileiros. Justifica-se, também, por oferecer ferramentas informatizadas, conforme SEESP/MEC-2002, "que permitem compensar uma ou mais limitações funcionais motoras, sensoriais ou mentais da pessoa com deficiência, com o objetivo de permitir-lhe superar as barreiras da comunicação e da mobilidade", e, no caso específico deste Projeto para alunos com necessidades educacionais especiais que apresentam durante o processo educacional "dificuldades de comunicação e sinalização diferenciada dos demais alunos demandando a utilização de linguagens e códigos aplicados".

\section{OBJETIVO}

Este projeto pretende facilitar a comunicação e a integração de alunos com necessidades educativas especiais (Surdos e Deficientes Auditivos), seus pares, educadores e demais alunos. Aspira, também, apresentar e divulgar a LIBRAS de modo atraente e agradável para crianças surdas e ouvintes. Outra pretensão é a promoção do aprendizado do alfabeto manual (datilológico) e desta língua, que foi reconhecida muito 
recentemente (LEI N ${ }^{\circ}$ 10.436, DE 24 DE ABRIL DE 2002). E, como todos os JOGOS EDUCATIVOS, pretende ser um elemento do processo de ensino/aprendizagem que possibilite a assimilação de conteúdos acadêmicos e a inclusão social e digital de alunos e professores de maneira agradável e harmoniosa.

\section{INFORMÁTICA, JOGO E EDUCAÇÃO}

Este trabalho, cujo tema é a construção de um software que auxilie a criança surda no seu processo de desenvolvimento / aprendizagem, após a análise das várias possibilidades do uso da informática na educação, entre estas os jogos, optou-se pelo desenvolvimento de software educacional na forma de jogo.

Santos, 1998, p. 99, sugere a introdução de "tecnologias de multimídia como uma alternativa lúdica" e de preparo das novas gerações no uso do computador, e, também, "utilizar os jogos artesanais como suporte de criação de software".

Foi definido que os software sejam desenvolvidos visando-se a possibilidade de que possam ser utilizado por diferentes classes socioeconômicas, pois as escolas, incluindo as públicas, estão cada vez mais inseridas no mundo digital. Não há mais como negar à educação, em todos os seus níveis, o uso de tecnologias de ponta, num mundo cada vez mais informatizado, pois mesmo existindo quem pense que as modernas tecnologias sejam simples "instrumentos de transmissão" a capacidade dos computadores "ultrapassa bastante este plano redutor", sendo eles "um novo tipo de produto social", não podemos deixar de oferecer acesso a eles a determinados segmentos da sociedade, sob pena de ampliar a distância existente entre os que "têm" e os que "não têm", pois os computadores "não são meros produtos de consumo imediato, trazem acoplados novos rumos para aqueles que os utilizam." (Mrech, 1997, p. 63)

"Em todos os países, independentemente do seu grau de desenvolvimento, a informática tem sido um dos campos que mais tem crescido atualmente. Este processo tem atingido sobretudo as áreas de educação e lazer. Em decorrência, constata-se que, no mundo todo, o computador tem entrado cada vez mais cedo na vida das crianças. Torna-se, então, estratégico saber de que maneira ele pode determinar os novos rumos da construção do pensamento das crianças."

(Mrech, 1997, p. 62)

Raramente encontramos quem não esteja disposto a participar de um jogo, seja individual ou coletivo, seja uma atividade física ou mental, Grillo, 1979, pg. 92, "é difícil encontrar-se em nossos dias pessoas para quem o jogo, em suas diferentes modalidades, não seja algo contagiante e envolvente". Esta atração deve-se ao caráter lúdico e um certo descompromisso associado à ânsia de atingir determinado objetivo seguindo determinadas regras. Segundo Brougère, 1998, pg. 15, "quando o jogo se desenrola, há jogo no sentido de situação lúdica e presença de um jogo no sentido de sistema de regras".

A partir dos dois sentidos do jogo podemos ir mais além do que jogar, pode-se, segundo Brougère, 1998, pg. 15, "analisá-lo de um ponto de vista matemático, traduzi- 
lo num software, transformá-lo num espetáculo”. Dessa forma o jogo, como sistema de regras, subsiste independente dos jogadores, tornando-se jogo num segundo sentido quando se desenrola ao ser utilizado pelos jogadores.

Nem todo jogo é material pedagógico, como também, nem todo material pedagógico é jogo, segundo Cunha, 1995, p. 18, “o aspecto lúdico pode não estar presente" e Antunes, 1999, p. 38, acrescenta que:

"os jogos ou brinquedos pedagógicos são desenvolvidos com a
intenção explícita de provocar uma aprendizagem significativa,
estimular a construção de um novo conhecimento e,
principalmente, despertar o desenvolvimento de uma habilidade
operatória"

Jogo e brinquedo não são sinônimos; a semelhança está no fato de que são lúdicos, prazerosos. Porém o brinquedo não tem regras, nem necessariamente um objetivo a conquistar, começa e termina a qualquer momento. Ele não materializa um jogo, ele evoca um aspecto da realidade, micromundo, que a criança pode manipular de acordo com sua vontade; o jogo, também apoia-se num micromundo, mas não prescinde de regras, objetivo, começo e fim.

\begin{abstract}
“O brinquedo supõe uma relação com a infância e uma abertura, uma indeterminação quanto ao uso, isto é, a ausência de relação direta com um sistema de regras que organize sua utilização."
\end{abstract}

(Brougère, 1998, pg 89.)

O jogo é uma metáfora da vida, Brougère, 1998, Antunes, 1999, suas regras limitam e controlam uma situação criada, uma forma que, segundo Brougère, 1998, deve levar em consideração os interesses espontâneos da criança; porém não tem valor pedagógico em si mesmo devendo o pedagogo fornecer um conteúdo em forma de jogo ou selecionar jogos cujos conteúdos correspondam "a objetivos educacionais identificáveis". Sendo, então, que "o jogo é, efetivamente, uma situação artificial, limitada e controlada, implicando número restrito de parâmetros", isto não tira a espontaneidade do jogo, do jogo jogado, para ele a tese da "recapitulação permite justificar o valor educativo do jogo sem negar sua espontaneidade", o seu caráter ontogênico, pois, segundo Miranda, 1996, "o recém-nascido já traz consigo a aptidão ao lúdico quando brinca com o corpo, explorando seu novo espaço físico" aos poucos desenvolve-se progressivamente "até chegar, mais tarde, ao jogo de regras preestabelecidas" ou filogênico, segundo Marcellino, 1990, com a recapitulação das atividades ancestrais.

As atividades de aprendizagem deveriam ocorrer espontaneamente, sem coerção, sem o sentimento de obrigatoriedade, mas nem sempre isto acontece, embora o gosto por aprender seja um dos objetivos da educação. O jogo sendo uma emulação do 
cotidiano da vida envolve seus participantes de forma descomprometida em atividades não rotineiras que levam ao interesse, à curiosidade, à criatividade, como, também, à solução de problemas. Segundo Dorfmam, 1980, pg. 55, "ao se deparar com um jogo, o indivíduo encara uma situação-problema”, quando já conhece o jogo, ele busca suas regras, pensa em estratégias e formas para chegar à vitória; num jogo desconhecido dedica-se a aprendê-lo, procura ajuda, lê suas regras, resultando numa aprendizagem que o habilite a vencer.

"Utilizando a prática do jogo estaremos iniciando a alfabetização formal de maneira prazerosa, onde o medo de errar ou a expectativa de aprovação sejam superadas pela descoberta e emoção do aprender."

(Kusiack, 1994, p. 61)

Kuethe, 1978, recomenda que o professor utilize jogos ligados aos conteúdos que estão sendo trabalhados, "o que desejamos frisar é simplesmente que uma atividade que causa prazer aos estudantes e é compatível com os valores da educação deve ser incorporada ao processo ensino-aprendizagem". O autor ainda alerta para o fato de que os jogos não são exclusividade de crianças; o jogo educativo é estimulante para todas as faixas etárias, sendo é "um erro supor que os estudantes de mais idade não se interessam por atividades desse gênero" (Kuethe, 1978).

"O brinquedo e os brinquedos são excelentes oportunidades para nutrir a linguagem da criança. $\mathrm{O}$ contato com diferentes objetos e diferentes situações estimula também a linguagem interna e o aumento do vocabulário".

(Cunha, 1995, p. 10)

Pode-se fazer uma analogia entre o jogo e o ensino: ambos exigem que se aprenda algo, requerem dedicação e esforço e têm objetivos a conquistar. Grillo, 1979, citando Phenix, identifica várias características do jogo relacionadas com o ensino: voluntariedade, cotidiano (metáfora da vida), livre (espontâneo), tensão (na competição), delimitação de tempo e espaço, organização e sociabilidade.

O quadro que segue apresenta estas características: 


\begin{tabular}{|c|c|c|}
\hline & JOGO & ENSINO \\
\hline Voluntariedade & Livre de coerção ou castigos & $\begin{array}{l}\text { Aprende de forma compulsiva, } \\
\text { tendendo a gerar resistência à } \\
\text { aprendizagem }\end{array}$ \\
\hline Cotidiano & $\begin{array}{l}\text { É uma emulação caricata da } \\
\text { vida, quebrando a rotina e a } \\
\text { monotonia. }\end{array}$ & $\begin{array}{lll}\text { Deveria } & \text { relacionar-se com a } \\
\text { vida, provocando } & \text { a } \\
\text { curiosidade e estimulando a } \\
\text { imaginação }\end{array}$ \\
\hline $\begin{array}{l}\text { Livre } \\
\text { (espontâneo) }\end{array}$ & $\begin{array}{l}\text { Não exige obrigatoriedade, é } \\
\text { menos utilitário. }\end{array}$ & $\begin{array}{l}\text { Deveria ocorrer naturalmente } \\
\text { e não como uma imposição. }\end{array}$ \\
\hline Tensão & $\begin{array}{l}\text { O jogo traz em si uma } \\
\text { atmosfera de tensão, o desejo } \\
\text { de atingir a vitória aumenta o } \\
\text { ânimo e entusiasmo de jogar. }\end{array}$ & $\begin{array}{l}\text { A competição é válida quando } \\
\text { há respeito e consideração } \\
\text { pelo outro, usá-la no ensino } \\
\text { deve ser na busca de melhor } \\
\text { desempenho e autorealização. }\end{array}$ \\
\hline Tempo e espaço & $\begin{array}{l}\text { Tem realizado sua ação num } \\
\text { determinado tempo e espaço. }\end{array}$ & $\begin{array}{l}\text { A explosão de informações e } \\
\text { exigências a que o aluno é } \\
\text { submetido leva a uma } \\
\text { delimitação de tempo e } \\
\text { espaço, onde ele atuando } \\
\text { como um bom jogador } \\
\text { concentra seus esforços e } \\
\text { atenção para obter êxito em } \\
\text { seus objetivos. }\end{array}$ \\
\hline Organização & $\begin{array}{l}\text { É sempre organizado, tem } \\
\text { regras preestabelecidas e com } \\
\text { atividades sistematizadas, isto } \\
\text { não retira sua características } \\
\text { de liberdade, na verdade ela se } \\
\text { faz presente através da ordem. }\end{array}$ & $\begin{array}{l}\text { Deve ser organizado, ter } \\
\text { regras adequadas, que não } \\
\text { retiram a liberdade. A ordem e } \\
\text { a disciplina não devem ser } \\
\text { impostas, mas, percebidos } \\
\text { pelo aluno como algo que vem } \\
\text { de seu interior e aceita } \\
\text { conscientemente. }\end{array}$ \\
\hline Sociabilidade & $\begin{array}{l}\text { É social, tendo suas regras } \\
\text { aceitas e vividas pelos } \\
\text { participantes, formando uma } \\
\text { comunidade, porém apenas } \\
\text { quando o jogo se desenrola. }\end{array}$ & $\begin{array}{l}\text { É eminentemente social, suas } \\
\text { regras são aceitas e vividas } \\
\text { pelo grupo, diferencia-se do } \\
\text { jogo ao não sofrer solução de } \\
\text { continuidade, "por ser o } \\
\text { ensino um processo continuo, } \\
\text { onde cada sequiência que se } \\
\text { completa é a base e origem de } \\
\text { outra". }\end{array}$ \\
\hline
\end{tabular}

Quadro adaptado de Phenix, em Grillo, 1979:

Sendo uma característica do jogo a ludicidade, reportamo-nos a Marcellino, 1990, p. 50, que faz um questionamento e desafio: "Por que então não trilhar de fato o caminho das possibilidades abertas pela vivência do lúdico, no lazer, procurando transformar essas possibilidades em alternativa no campo da educação?" e, acrescenta, 
Marcellino, 1990, p. 57, "acredito que negar a possibilidade de manifestação do lúdico é negar a esperança."

"É pelo fato do jogo ser um meio tão poderoso para a aprendizagem das crianças que, em todo lugar onde se consegue transformar em jogo a iniciação à leitura, ao cálculo, ou à ortografia, observa-se que as crianças se apaixonam por essas ocupações comumente tidas como maçantes."

(Jean Piaget, 1998)

Segundo Bortoli, 2000, a literatura disponível aponta "vários livros que estimulam o uso de jogos na educação com dezenas de exemplos dos mais variados tipos e diferentes classificações" e indica "a opção por utilizar como recurso o jogo no computador, justificado pelo estímulo e desafio proporcionado, envolvendo de forma lúdica, natural e prazerosa os alunos, tendo como alvo os objetivos de ensino" que se pretende alcançar. Dentre os possíveis jogos encontramos os tradicionais "Jogo da Memória", "Quebra-Cabeças" e "Construtor (Pequeno Arquiteto)", além destes foram criados novos tais como "Quantificação e Ordenação ", "Zetopéia", "Lateralidade e Partes do Corpo" e "Meus Primeiros Sinais em LIBRAS", todos já concluídos ou em desenvolvimento.

\section{DESENVOLVIMENTO}

As atividades foram idealizadas de forma a proporcionar ao educando oportunidades de aprender, observar, analisar, decidir, pintar, associar, memorizar, criar livremente ... utilizando objetos virtuais, num ambiente informatizado, embora, a princípio, estejam direcionado à crianças com idade entre 3 e 11 anos, seu uso não se restringe necessariamente a esta faixa etária, sabendo utilizar o mouse elas já podem ser exploradas pela maioria dos usuários sozinhos, no entanto, o acompanhamento pelos pais, professor, pedagogo, sociólogo, fonoaudiologo, fisioterapeuta, terapeuta ocupacional e profissionais afins pode ajudar no desempenho do usuário.

São projetos feitos a partir de idéias simples, porém demandam bastante tempo e trabalho e, embora, construídos com um sistema de autoria de multimídia exigem muito conhecimento na área da educação e em programação.

\section{PLATAFORMA/CONFIGURAÇÃO MÍNIMA}

Os programa foram desenvolvidos para o SO Windows, cuja base instalada é de aproximadamente $97 \%$ dos PCs.

IBM PC compatível

WIN 95/98/ME/XP (Testes feitos no WIN 2000 e no Win NT foram positivos)

Processador $133 \mathrm{mHz}$ - $1 \mathrm{MB}$ de memória de vídeo - $32 \mathrm{MB}$ RAM

De 15 a $50 \mathrm{MB}$ de HD (no micro ou CD), dependendo de cada programa

$1 \mathrm{~kb}$ de HD em cada estação (se instalado em CD ou num servidor de rede)

CD-ROM 6x (se opção for executar com o programa instalado em CD)

Monitor: Resolução do: 800x600 pixels - Cores:16 bit color

Fontes: tamanho -> pequenas - instaladas: Arial, Times New Roman, Courier New

Mouse

Placa de som: blaster ou compatível.

Windows Media Player ou compatível

V.3 $\mathrm{N}^{\mathrm{o}} 1$, Maio, 2005 
Controlador MCI - Media Command Interface - instalado.

7. PROGRAMAS DESENVOLVIDOS E EM DESENVOLVIMENTO:

- "Quantificação e Ordenação (**)

- "Zetopéia" (**),

- "Jogo da Memória" (*)

- $\quad$ "Lateralidade e Partes do Corpo" (*)

- "Quebra-Cabeça" (*)

- "Construtor" (*)

- "Cubos" (*)

- $\quad$ "Meus Primeiros Sinais em LIBRAS" (*)

Obs.: Estão assinalados com $(*)$ os programas em fase de desenvolvimento e testagem e com $(* *)$ os programas já prontos e disponíveis na Internet (http://www.editora-araraazul.com.br/arara brinquedo.php)

A seguir seguem a descrição, atividades e objetivos de alguns deles.

\section{ZETOPÉIA}

(Abecedário)

O Zetopéia é um bichinho muito instruído, seu conhecimento não está na "ponta da língua", mas, em cada um dos segmentos de seu corpo. Ele sabe todo o alfabeto, quando você colocar uma parte do corpo no lugar correto, em ordem alfabética, suas perninhas se movem, sempre que o alfabeto estiver completo e em ordem ele fica feliz e balança as anteninhas.

São três opções: alfabeto completo, vogais e consoantes. Em todas elas estão disponíveis os alfabetos fonético e manual (dactilológico), o som das letras, uma palavra e uma figura cuja primeira letra corresponde cada uma das letras do alfabeto.

O objetivo da atividade é auxiliar na aprendizagem dos alfabetos manual e fonético, colocando as perninhas em ordem alfabética. Podendo ser utilizado por surdos e ouvintes, espera-se estar na integração de surdos e ouvintes.

\section{Movimentação dos segmentos/pernas (funcionamento do programa)}

Os segmentos podem ser movidos livremente. Basta levar a seta (apontador do mouse) até o objeto (ela torna-se uma mão), então, pressione o botão esquerdo do mouse e, mantendo o botão pressionado, arraste o objeto até o local desejado e solte o botão.

Quando o segmento está na parte correta do corpo do Zetopéia, a perninha fica mexendo-se e as imagens alternam-se: alf. manual $\Rightarrow$ alf. fonético maiúsculo (bastão) $\Rightarrow$ alf. fonético minúsculo $\Rightarrow$ desenho. Quando todas as pernas estiverem no lugar correto as antenas do Zetopéia balançam.
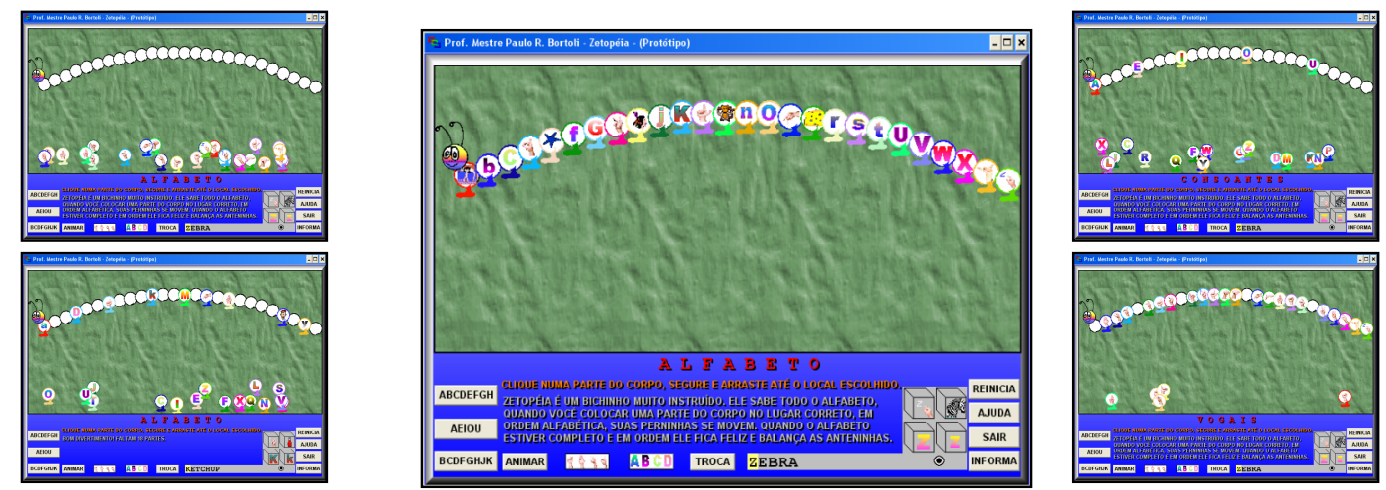


\section{QUEBRA-CABEÇA \\ (Quantificação e Ordenação)}

Este software lúdico/pedagógico é um quebra-cabeça formado por dez aquários, eles contêm de zero (vazio) até nove peixinhos nadando e dez números (de zero a nove), o usuário deve montar fazendo coincidir cada aquário com o número (dactilológico ou arábico) correspondente: aquário vazio com o zero, aquário com um peixe com o número um, aquário com dois peixes com o número dois...

São duas opções, uma explora mais especificamente a capacidade de ordenação e outra a da quantificação, de zero a nove.

\section{Objetivos}

\section{Objetivo da atividade}

- colocar cada peça sobre o número ou o aquário correspondentes.

\section{Objetivos pedagógicos}

- trabalhar com ordenação e quantificação de zero a nove;

- trabalhar com a idéia de conjunto;

- aprender o valor representativo dos numerais de zero a nove, utilizando algarismos arábicos ou dactilológicos;

- associar as partes dos quebra-cabeças que representam conjuntos de elementos (aquários) com os números;

- associar as partes dos quebra-cabeças que representam idéia de quantidade (números) com os aquários;

- aprender os algarismos dactilológicos e arábicos.

\section{Movimentação dos objetos (funcionamento do programa)}

Os objetos podem ser movidos livremente, basta levar a seta (apontador do mouse) até o objeto (ela torna-se uma mão), então, pressionar o botão esquerdo do mouse e, mantendo o botão pressionado, arrastar o objeto até o local desejado e ali soltar o botão. Os objetos animados suspendem a animação enquanto estão selecionados e estão dispostos em camadas, assim, é possível colocar os que estão nas camadas superiores sobre os das inferiores.
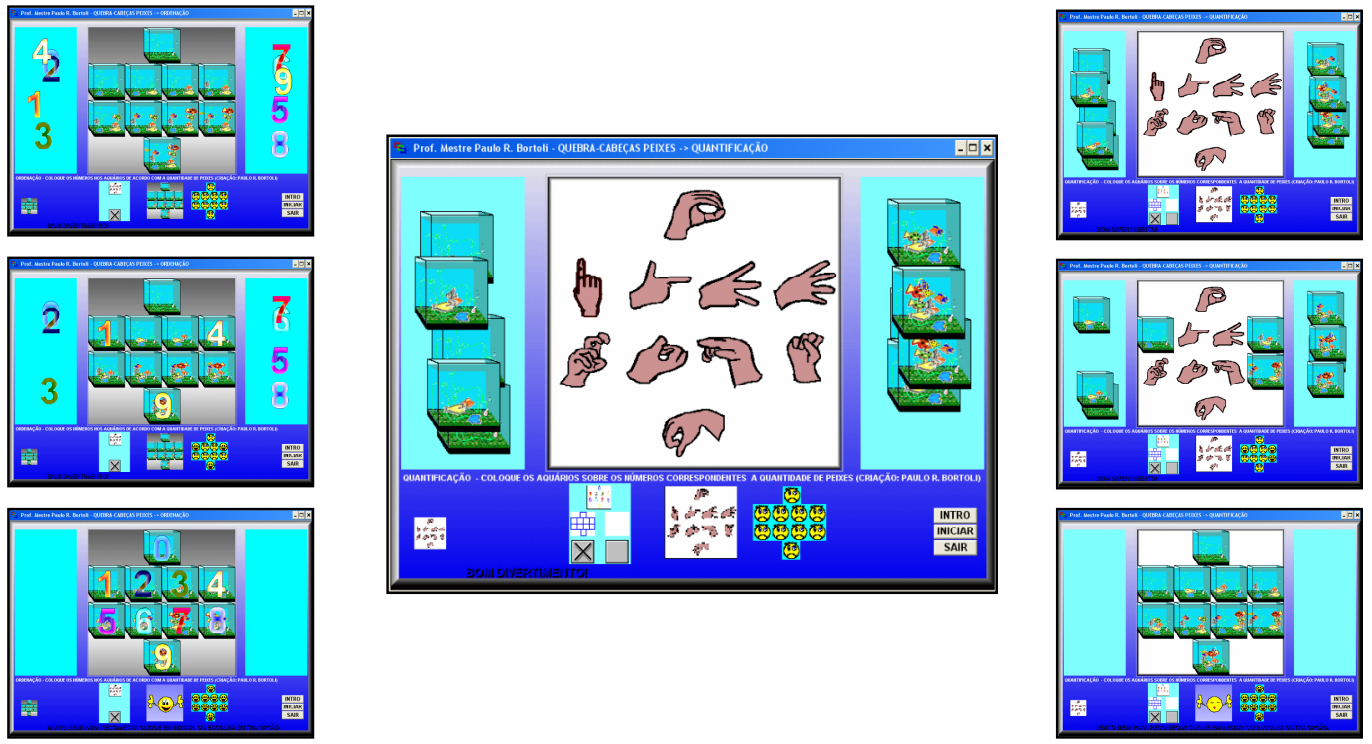


\section{NOSSO CORPO}

(Lateralidade e partes do corpo)

Esta atividade apresenta as imagens de uma menina e de um menino, é um quebra-cabeças do corpo humano. Sempre que é iniciado as partes do corpo (cabeça, tranco e membros) são distribuídas aleatoriamente e devem ser montadas sobre a figura fundo.

A atividade foi desenvolvida para trabalhar a lateralidade e partes do corpo, tem duas opções imagens de frente e de costas. A cada peça movida ou tocada pelo usuário é projetado um vídeo legendado e com narração em LIBRAS e português oral.

\section{Movimentação dos objetos (funcionamento do programa)}

Os objetos podem ser movidos livremente, basta levar a seta (apontador do mouse) até o objeto (ela torna-se uma mão), então, pressionar o botão esquerdo do mouse e, mantendo o botão pressionado, arrastar o objeto até o local desejado e ali soltar o botão. Sempre que uma parte é colocada no local correto a carinha corresponde aquela posição sorri, quando o quebra-cabeça estiver montado corretamente são distribuídos "beijos".
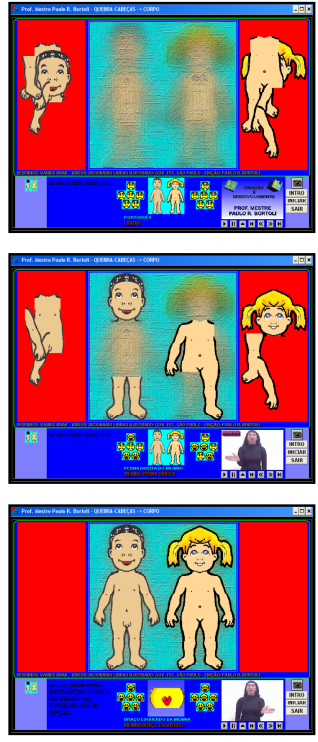
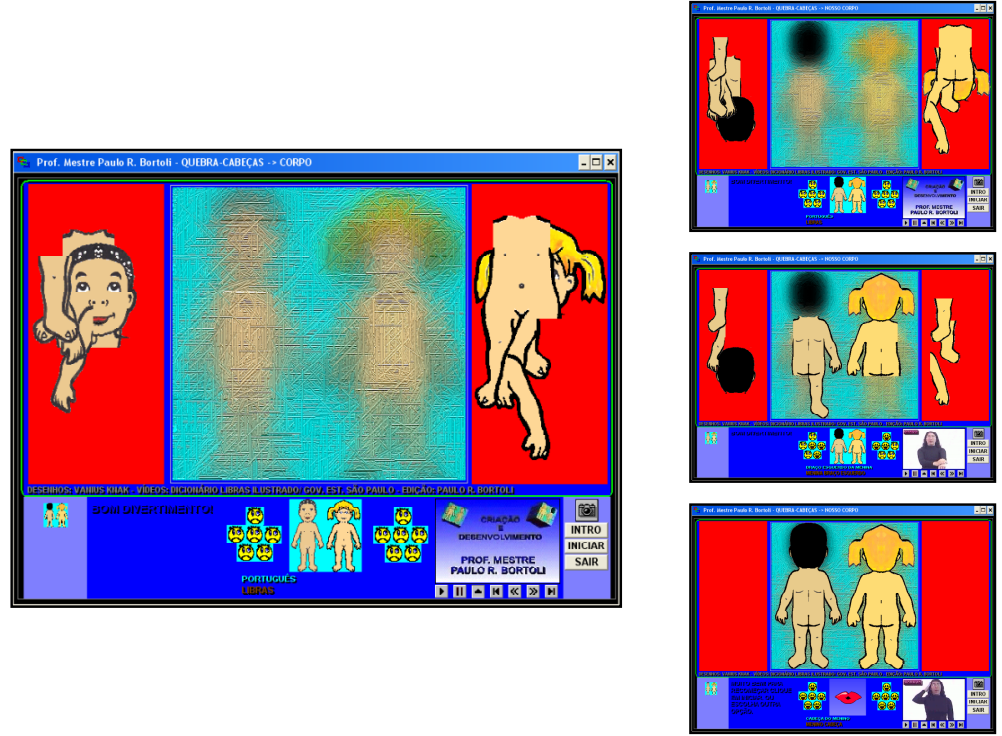

\section{JOGO DA MEMÓRIA}

(Algarismos e vogais do alfabeto manual e fonético)

Este jogo diferencia-se do tradicional, pois não exige a procura de cartas iguais, tendo como objetivo auxiliar na aprendizagem da correspondência entre os caracteres fonéticos dos algarismos e vogais e os sinais manuais dos algarismos e vogais, outros objetivos são desenvolvimento da percepção visual, reconhecimento da posição de objetos, memória, atenção e concentração, através da localização de figuras. 


\section{Funcionamento do jogo}

É constituído por um tabuleiro com 30 peças, que formam 15 pares de cartas com caracteres fonéticos dos algarismos e vogais e os sinais manuais dos algarismos e vogais. As cartas são distribuídas aleatoriamente no início de cada jogo e ficam com a imagem voltada para baixo. O jogador deve clicar sobre elas procurando os pares, sempre que formarem pares elas ficam viradas para cima, caso contrário são mostradas durante alguns segundos e depois viradas para baixo. O jogo termina quando todos os pares são encontrados
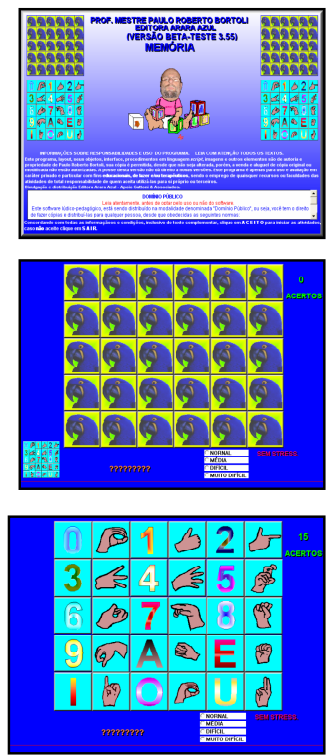
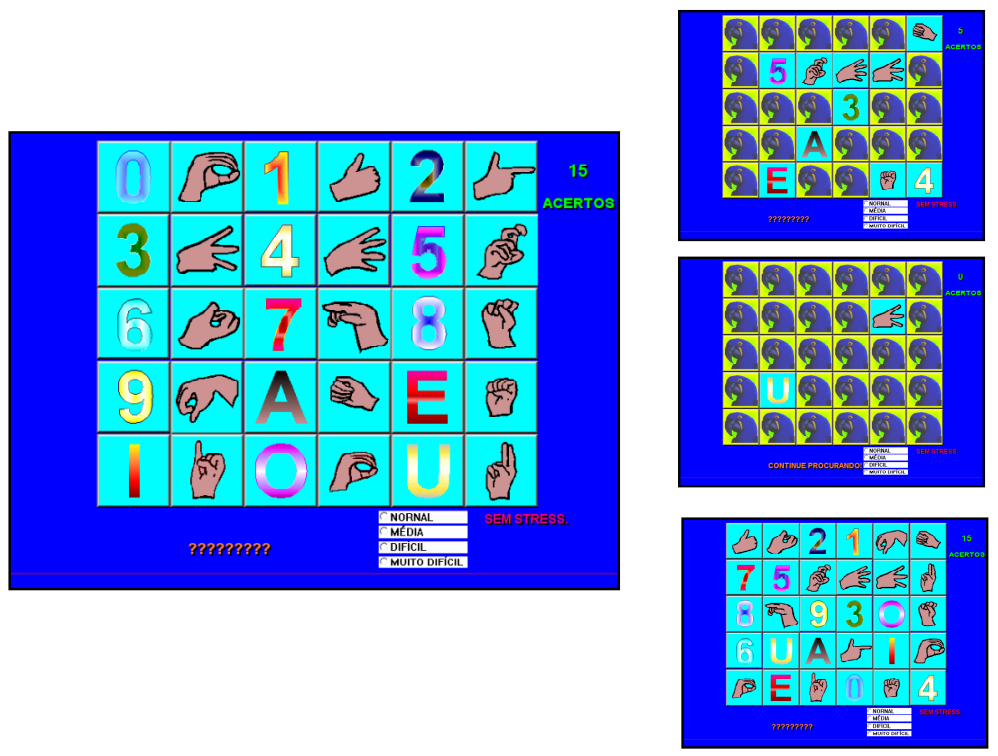

\section{CONCLUSÃO}

ARARA DE BRINQUEDO é um PROJETO inovador porque disponibiliza atividades lúdicas e educativas em LIBRAS e alfabeto manual para crianças surdas e ouvintes, podendo estas serem acessadas, para download, gratuitamente através da Internet no site da Editora (www.editora-arara-azul.com.br), em E-BOOKS $\Rightarrow$ PROJETO ARARA DE BRINQUEDO.

Este Projeto que pretende facilitar a comunicação e a integração de alunos com necessidades educativas especiais, seus pares e seus educadores. Objetiva, também, apresentar e divulgar a LIBRAS de modo atraente e agradável para crianças surdas e ouvintes. Outra pretensão é a promoção do aprendizado desta língua, que foi reconhecida muito recentemente (LEI No 10.436, DE 24 DE ABRIL DE 2002). Com o Projeto diligencia-se através das atividades, jogos lúdico-pedagógicos digitais, oferecer mais um elemento, ao processo de ensino/aprendizagem, que possibilite a assimilação de conteúdos acadêmicos como, também, inclusão social de maneira dinâmica, agradável e harmoniosa.

A certeza de que este é um caminho promissor no atendimento das necessidades educacionais dos surdos, é fato de que o Projeto já foi objeto de reportagem na TV Educativa / RIO, março de 2005, após a qual recebeu-se e-mail de várias pessoas e entidades ligadas a surdez solicitando os programas em CD-ROM. No entanto, no momento não é possível, pois, pela sua especificidade, envolve um grande volume de investimento em recursos tecnológicos, humanos e financeiros. Assim sendo, para sua 
continuidade e distribuição em mídia CD-ROM, dependerá de apoio e patrocínio externos.

\section{REFERÊNCIAS BIBLIOGRÁFICAS}

ANTUNES, Celso. Jogos para a estimulação das múltiplas inteligências. Petrópolis, RJ, Vozes, $2^{a}$ edição, 1999.

, Celso. Manual de técnicas de dinâmica de grupo de sensibilização de ludopedagogia. Petrópolis, RJ, Vozes, 17ª edição, 1999.

AZEVEDO, Breno Fabricio Terra. Tópicos em Construção de Software Educacional. Disponível em: <http://www.inf.ufes.br/ tavares/trab3.html> Acesso em: 21 mar. 1999.

BORTOLI, Paulo Roberto. Software educacional lúdico: uma ferramenta para auxiliar o surdo no processo de construção de seu vocabulário escrito. - Fac. de Educação, PUCRS/Porto Alegre, 2000. 288 p. Dissertação de Mestrado.

BROUGÈRE, Gilles. Jogo e Educação. Porto Alegre, RS, ARTMED, 1998.

CAMPOS, Fernanda, CAMPOS, Gilda, ROCHA, Ana Regina. Dez etapas para o desenvolvimento de software educacional do tipo hipermídia. Disponível em: $<$ http://phoenix.sce.fct.unl.pt/ribie/cong_1996/CONGRESSO_HTML/19/ETAPAS.html \#DEZ ETAPAS PARA>. Acesso em: 27 dez. 1999.

CICCONE, Marta. Comunicação Total: Introdução, Estratégias a Pessoa Surda. $2^{\circ}$ ed. Rio de Janeiro: Cultura Médica, 1996.

COSTA, Fernando Albuquerque. Concepção de sistemas de formação multimédia: elaboração de um Guião de Autor. Disponível em:

$<$ http://www.minerva.uevora.pt/simposio/comunicacoes/fcosta/guiautor.htm>. Acesso em: 27 nov. 1998.

COSTA, Rosa M. E. M. TREINAR: Um Tutor Inteligente para Treinamento em Sistemas baseados em Conhecimento. In: Anais do VI Simpósio Brasileiro de Informática na Educação. Florianópolis. Nov./1995.

CUNHA, Nylse Helena da Silva. Brinquedo, desafio e descoberta. Subsídios para utilização e confecção de brinquedos. Brasília, DF, FAE, 1ª edição/ $3^{\text {a }}$ tiragem, 1995.

DORFFMAM, M. T. O Jogo e a Criatividade. Caderno n. ${ }^{\circ}$ 3, PUCRS. Porto Alegre. EPECE, 1980.

FRITZEN, Silvino José. Jogos dirigidos para grupos, recreação e aulas de educação física. Petrópolis, RJ, Vozes, 23ª edição, 1998.

GADOTTI, Moacir. História das Idéias Pedagógicas. São Paulo, SP, Editora Ática, 1993. 
GÓES, Maria Cecília Rafael de. Linguagem, Surdez e Educação. Autores Associados, 1996.

GONÇALVES, Berenice. Hipermídia Pedagógica. Disponível em: $<$ http://www.cce.ufsc.br/ ulbricht/hipermidia_ensino/resumo(2.1).html>. Acesso em: 15 abr. 1999.

GRILLO, Marlene In: SANT’ANNA, Flávia Maria et alii. Dimensões Básicas do ensino. Rio de Janeiro, RJ , Livros Técnicos e Científicos Editora, 1979.

INES - Instituto Nacional de Educação de Surdos- Disponível em: <http://www.ines.org.br/ines_livros/3/3_PRINCIPAL.HTM>. Acesso em: 29 set. 2000.

KHERIAT, Larry. SuperLink para Windows - Versão 2.0 - Washington Computer Services. Rio de Janeiro. IBM, 1994.

KUETHE, James L. O Processo Ensino-Aprendizagem. Porto Alegre, RS, Globo, 1978.

KUSIACK, Gigela Ingrid. O jogo na 1. a Série. In: Anais II seminário Internacional de Alfabetização \& Educação Científica. Ijui - RS - 1994.

LDB - Lei de Diretrizes e Bases da Educação Nacional (1996) - LEI N. 9.394, de 20 de dezembro de 1996.

MACEDO, Alessandra Alaniz, KUTOVA, Marcos André Silveira. Reuso De Software. Disponível em:

$<$ http://www.intermidia.icmsc.sc.usp.br/ kutova/monografias/reuso.html>. Acesso em: 20 mar. 1999.

MARCELLINO, Nelson Carvalho. Pedagogia da Animação. Campinas, SP. Papirus, 1990.

MEDEIROS, Marco Aurélio. Ferramentas de concepção de interfaces homemmáquina. Disponível em: <www.ctai.rct-sc.br/revista/artigo3.html>. Acesso em: 14 out. 1999.

MIRANDA, Simão de. Essa, você aprende brincando! Atividades recreativas para sala de aula. Campinas, SP, Papirus, $2^{a}$ edição, 1996.

MRECH, Leny Magalhães. A Criança e o Computador. In: SANTOS, Santa Marli Pires dos (Org.). O lúdico na formação do educador. Petrópolis, RJ, Vozes, $3^{\text {a }}$ edição, 1999.

Leny Magalhães. O uso de brinquedos e jogos na intervenção sociopedagógica de crianças com necessidades especiais. Disponível em:

$<$ http://www.regra.com.br/educacao/usobrin.htm>. Acesso em: 30 mar. 2000.

ORSO, Darci. Atividades Recreativas - Resgatando o prazer de brincar. 1997.

PETRY, Rose Mary \& QUEVEDO, Zeli. A magia dos jogos na alfabetização. Porto Alegre, RS, Kuarup, $2^{a}$ edição, 1993. 
PIAGET, Jean. Psicologia e Pedagogia. Rio de janeiro. Forense Universitária, 1998.

REVERBEL, Olga \& OLIVEIRA, Sandra R. Ramalho. Vamos alfabetizar com jogos dramáticos? atividades básicas. Porto Alegre, RS, Kuarup, 3ª edição, 1994.

SANTOS, Santa Marli Pires dos ( Org.). Brinquedoteca: o lúdico em diferentes contextos. Petrópolis, RJ, Vozes, $3^{\text {a }}$ edição, 1998.

Secretaria se Educação Especial/MEC. Saberes e práticas da inclusão : dificuldades de comunicação e sinalização: surdez đ 2. ed. rev. - Brasília : MEC, SEESP, 2003.

Secretaria de Educação Especial/MEC. Portal de ajudas técnicas para educação: equipamento e material pedagógico para educação, capacitação e recreação da pessoa com deficiência física: recursos pedagógicos - Brasília: MEC: SEESP, 2002, fasc. 1.

SILVA, Carla Cilene Babtista da. O lugar do brinquedo e do jogo nas escolas especiais de educação infantil. Tese de Doutorado - USP. São Paulo /SP 2003.

SKLIAR, Carlos (Org.). Atualidade da educação bilíngüe para surdos. Interfaces entre pedagogia e lingüística. Porto Alegre, RS, Mediação, 1999. V.2.

VALENTE, J. V. Análise dos Diferentes Tipos de Software Usados na Educação. Disponível em: <http://www.proinfo.gov.br/testosie/prf_txtie2.htm>. Acesso em: 06 mai. 1999.

WOLFGRAM, Douglas E. Criando Multimídia. Rio de Janeiro, RJ, Editora Campus, 1994. 